\title{
LUT
}

Lappeenranta

University of Technology

\section{Pattern recognition algorithm for analysis of chugging direct contact condensation}

Hujala Elina, Tanskanen Vesa, Hyvärinen Juhani

This is a Final draft version of a publication

published by Elsevier

in Nuclear Engineering and Design

DOI: $10.1016 /$ j.nucengdes.2018.03.032

Copyright of the original publication: ( Elsevier 2018

Please cite the publication as follows:

Hujala, E., Tanskanen, V., Hyvärinen, J. (2018). Pattern Recognition Algorithm for Analysis of Chugging Direct Contact Condensation. Nuclear Engineering and Design, Vol 332, Issue June 2018. p. 202-212. DOI: 10.1016/j.nucengdes.2018.03.032 


\title{
Pattern Recognition Algorithm for Analysis of Chugging Direct Contact Condensation
}

\author{
Elina Hujala*, Vesa Tanskanen, Juhani Hyvärinen \\ LUT School of Energy Systems, Nuclear Engineering, Lappeenranta University of \\ Technology (LUT), P.O.Box 20, FIN-53851 Lappeenranta, Finland
}

\begin{abstract}
Direct contact condensation of steam bubbles in a boiling water reactor suppression pool has long been studied utilizing video recording of experiments. The use of video recording enables observation of the behaviour of the bubble surface area and can assist in validation of computational fluid dynamics models.
\end{abstract}

A direct contact condensation experiment of the suppression pool test facility PPOOLEX was recorded using high-speed cameras. The recorded video material was used for development of a pattern recognition and data analysis algorithm. $300 \mathrm{fps}$ video of $48 \mathrm{~s}$ duration was cut into frames with a resolution of $768 \mathrm{px} \times 768 \mathrm{px}$. The side profile of the bubbles was identified and the volumes and surface areas of the bubbles were evaluated using a voxel-based method.

The purpose of the algorithm was to determine the shape and size of steam bubbles during their formation, expansion, collapse and re-formation. The most probabilistic chugging frequencies were estimated. The bubble

\footnotetext{
*Corresponding author. Tel.: +358 401529406

Email address: Elina.Hujala@lut.fi (Elina Hujala)
} 
geometry data were also used to determine the velocity and acceleration of the phase interface, as condensation induced Rayleigh-Taylor instability develops on the bubble surface during the bubble collapse, as the heavy phase accelerates towards the light phase. Knowledge of the critical wave length is necessary for mesh spacing in CFD calculations.

The algorithm appears to be promising. Some limitations exist and approximations need to be made due to the challenging video shooting conditions. The algorithm works well for cylindrical bubbles and provides important data on the dynamics of the phase interface necessary for numerical modelling of direct contact condensation.

Keywords: BWR suppression pool, Direct contact condensation, Chugging, Rayleigh-Taylor instability, Pattern recognition, CFD 


\section{Nomenclature}

\section{Variables}

$\begin{array}{llll}\mathbf{a} & \text { acceleration } & \mathbf{V} & \text { vertex array } \\ A & \text { surface area } & y & \text { distance } \\ d & \text { size of a one pixel } & |Y(f)| & \text { absolute value of amplitude } \\ d_{i} & \text { number of nonzero elements of a row } & & \\ f & \text { frequency } & \text { Subscripts } & \\ \text { Fs } & \text { frame rate } & & \\ \mathbf{F} & \text { face array } & i & \text { index } \\ h_{i} & \text { height } & l & \text { liquid (water) } \\ \lambda_{c} & \text { critical wavelength } & s & \text { element } \\ \lambda_{m} & \text { predominant wavelength } & v & \text { vapour (steam) } \\ M_{i} & \text { number of pixels } & & \end{array}$

$n \quad$ image number

Abbreviations

$N \quad$ total number of images/cylinders

$r_{i} \quad$ radius

BWR boiling water reactor

$r_{i, s} \quad$ vertices

CFD

computational fluid dynamics

$\rho_{l} \quad$ density of liquid

DCC

direct contact condensation

$\rho_{v} \quad$ density of vapour

FFT

fast Fourier transform

$S$ patch area

fps

frames per second

$\sigma \quad$ surface tension

LOCA

loss of coolant accident

$t$ time

PACTEL parallel channel test loop

$\mathbf{v}_{i} \quad$ vertex vector

PIV

particle image velocimetry

v velocity

(P)POOLEX condensation pool experiments

V volume

3

WMS wire-mesh sensor 


\section{Introduction}

Direct contact condensation (DCC) of saturated steam in subcooled water can cause rapid pressure transients and accelerate the liquid to high velocity, leading to high dynamic loads on surrounding structures. These loads are encountered in many engineered systems e.g. in the form of instantaneous water hammer in pipes or as periodic condensation oscillations of submerged steam injections. DCC is, however, an essential phenomenon in certain nuclear engineering applications such as steam-driven water injection systems and suppression pools.

Liquid phase turbulence near the gas-liquid interface and available interfacial area determine the DCC heat transfer coefficient. DCC is controlled by the liquid heat on the liquid side and by surface pollutants such as noncondensable gases on the gas side. The conduction dominated boundary layer on the liquid side can be thin, and heat transfer from the interface is controlled mainly by turbulent convection, i.e., eddies. Thus, a valid liquid side heat transfer correlation is the most important part when modelling DCC in mildly sheared and lowly subcooled stratified flows. However, if the subcooling is high and the interface is wavy or unstable, as on a bubble in a liquid, the interfacial area modelling has increased importance in the heat transfer solution. This importance is not only due to the increased heat transfer area in such conditions, but also due to the interface motion, which is two-way coupled with the liquid side turbulent heat transfer mechanism. That is, a higher DCC heat transfer rate causes suction on the interface, reshaping it and increasing the interfacial area. Waviness and other interfacial instabilities play a significant role in detemining the rate of interfacial area increase 
and the eddy size in the liquid side.

DCC of steam bubbles has long been an important research subject in study of boiling water reactor (BWR) suppression pools. In order to prevent pressure build-up, it can be essential to condense a large amount of steam rapidly, e.g., during a loss of coolant accident (LOCA) or safety relief valve operation. DCC is the most rapid and straightforward means to achieve rapid condensation. In BWR suppression pools, saturated steam is discharged through large submerged vent pipes into a deeply subcooled mass of water. In such a case, the condensation mass flow rate is high, and it is possible that the pressure decrease within the lighter phase causes interfacial accelerations higher than the acceleration of gravity. Interfacial accelerations of order of 100-1000 $\mathrm{m} \mathrm{s}^{-2}$ magnitude have been observed in suppression pool cases (Patel et al. 2017). Such high accelerations invoke interfacial instabilities, i.e., Rayleigh-Taylor (Strutt, 1883; Taylor, 1950), Kelvin-Helmholz (Drazin, 2002) and Richtmyer-Meshkov (Richtmyer, 1960; Meshkov, 1969; Brouillette, 2002) instability, which cause roughening of the steam-water interface. Interface roughening increases heat transfer rate Brennen, 2014), and thus also condensation heat transfer rate should increase temporarily. This recurrently increasing interfacial area together with high turbulence cause condensation oscillations and a phenomenon called chugging. In consequence, the steam injected to the pool causes high dynamic loads on the walls and internal structures. Due to the rapid movement of the phase interface, direct measurement of heat and mass transfer is impossible during chugging with existing techniques. However, DCC model validation against experiments becomes possible if the time evolution of the phase interface - 
its size and shape - can be determined.

As DCC has a major role in nuclear power plant safety, test facilities small Aya et al. 1980, Aya and Kobayashi, 1983, Aya and Nariai, 1987; Simpson and Chan, 1982; Gregu et al., 2017) and large (Motoaki Utamura and Uozumi, 1984; Kukita et al., 1984, 1987; Pellegrini et al., 2016) - have been used to study condensation modes. The experimental results have been used for improvement and validation of different condensation models of computational fluid dynamic (CFD) codes (Patel et al., 2017; Mimouni et al., 2011). Validation of CFD models for two-phase flows often requires measurement techniques that are currently not feasible (Bestion, 2014). In the case of DCC, some of these challenges can be addressed by using video recording of the experiments, analyzing the recorded films and comparing results to the simulations. Movie cameras or, more recently, modern high-speed cameras, have been utilized to record experiments (Chan and Lee, 1982; Issa et al., 2014). For decades, only ocular investigations of video material of condensing bubbles were mostly used to compare the results of the system codes, CFD models and simulations (Chan and Lee, 1982; Aust et al., 1983). Moreover, the analysis methods and findings of the ocular estimations were not reported extensively. Recently, however, more systematic means to take advantage of the video material have become more popular, see e.g. (Issa et al. 2014).

A preliminary pattern recognition algorithm has been presented for the former BWR suppression pool model, POOLEX test facility (Tanskanen et al. 2014b). The aim of the algorithm was to evaluate the size distribution and chugging frequencies of steam bubbles. The limited length of 
the available high-speed video material samples resulted in standard $25 \mathrm{fps}$ samples having to be used for algorithm development.

This current study presents an updated pattern recognition and data analysis algorithm for a direct contact condensation mode called chugging by making use of high-speed cameras and improved resolution images. The algorithm is based on experiments with the present-day pressurised suppression pool model, the PPOOLEX test facility. The aim of the study is to increase knowledge of DCC of steam bubbles. The algorithm estimates the change of volumetric and surface area distributions of the condensing steam bubbles and determines the velocities and accelerations of growing and collapsing bubbles. Additionally, chugging frequencies and surface instabilities are investigated in frequency analysis of the algorithm output.

\section{PPOOLEX DCC-05 experiment}

\subsection{PPOOLEX test facility}

The PPOOLEX test facility is a scaled thermal hydraulic model of a Nordic-type BWR suppression pool. It is a $31 \mathrm{~m}^{3}$ stainless steel vessel of $2.4 \mathrm{~m}$ diameter which consists of two parts: a wet well compartment (suppression pool) and a dry well compartment, separated by an intermediate floor, an inlet plenum and air/steam line piping. A route for air/steam flow from the dry well to the wet well is created by a vertical blowdown pipe attached non-axisymmetrically underneath the floor. The length and width of the blowdown pipe can be changed depending on the needs of the ongoing experiment. The assembly of the PPOOLEX test facility is shown in Fig. 1.

Steam needed in the experiments is produced with the PACTEL test 
Figure 1: PPOOLEX test facility. Locations of the high-speed cameras are also marked.

facility, which has three steam generators and a heating power of $1 \mathrm{MW}$ at the core section. The facility can be used to model various thermal hydraulic phenomena, such as steam bubble condensation and gas bubble propagation in suppression pools, structural loads caused by rapid condensation and the effect of non-condensable gases on emergency core cooling strainer behaviour. A more detailed description of the PPOOLEX test facility is presented in (Puustinen et al., 2013). 


\section{2. $D C C-05$ experiment}

The PPOOLEX DCC-05 test was a part of a direct contact condensation test program. The main purpose of DCC-05 was to obtain measurement data for validation of the DCC models used in CFD modelling of chugging and to make a high-speed video recording for use in development work of a pattern recognition algorithm (Tanskanen et al., 2014a; Hujala et al., 2013). The pool water temperature rise was kept as low as possible in the DCC05 test in order to study only the effect of the variable steam flow rate. The suppressed temperature increase was achieved by minimizing the steam injection during waiting times due to flow rate adjustments and camera data transfer processes. Before the experiment the wet well pool was filled with water at $298 \mathrm{~K}$ so that the blowdown pipe outlet was submerged by $1.05 \mathrm{~m}$ and the dry well was filled with air at atmospheric pressure. A DN100 stainless steel blowdown pipe was used in the experiment. The experiment was started with a clearing phase during which the structures were heated to prevent wall condensation and non-condensable air was removed from the dry well as much as possible. This was achieved by using a high steam flow rate (320. . 340 $\left.\mathrm{g} \mathrm{s}^{-1}\right)$ blow for $500 \mathrm{~s}$, filling the dry well with steam and pushing the air to the wetwell gas space. Pool temperature rose to $303 \mathrm{~K}$ during this process (Tanskanen et al., 2014a). The valid part of the experiment following the clearing phase consisted of six runs with increasing flow rates between $75 \mathrm{~g} \mathrm{~s}^{-1}$ and $200 \mathrm{~g} \mathrm{~s}^{-1}$. Pool temperature rose gradually to $313 \mathrm{~K}$ during these blows. The individual steam blows of the DCC-05 experiment defined by the steam mass flux and pool bulk temperature are in region 2 of the condensation mode map by Lahey and Moody (Lahey and Moody, 1993) 
presented in Fig. 2.

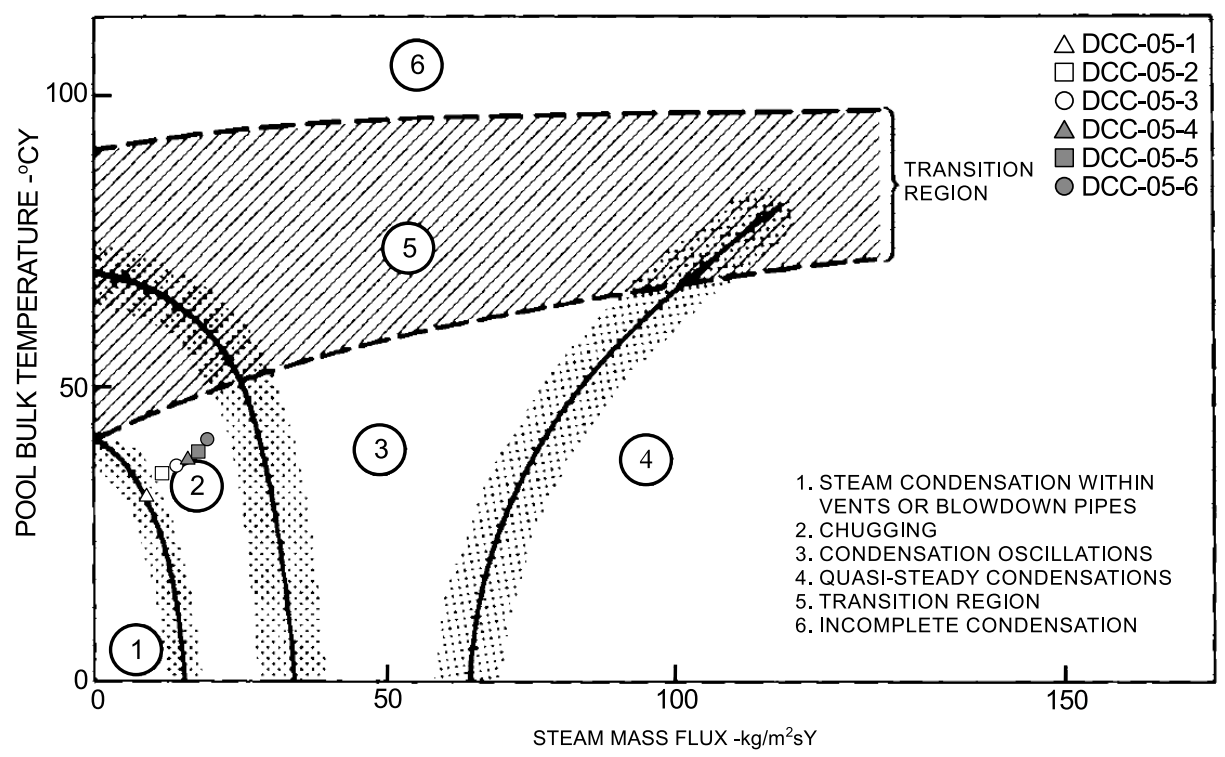

Figure 2: Steam blows of the DCC-05 experiment on the condensation mode map by Lahey \& Moody (Lahey and Moody, 1993). Chugging was the dominant DCC mode during the DCC-05 test.

The DCC-05 test consisted of six runs with different flow rates, named (DCC-05-1...DCC-05-6), with total length of 52 min. Each run had its own challenges with image quality. Lighting conditions caused blurred overexposed edges of the bubbles and, alternatively, shadowed edges. Swarms of small bubbles created bright additional objects, and transparent large bubbles were hard to recognize. Different issues hampering bubble image processing are presented in Fig. 3. This paper concentrates on test DCC-05-4, whose recorded video material appeared to have the best quality.

Test facility instrumentation comprised three Phantom Miro M/R/LC110 


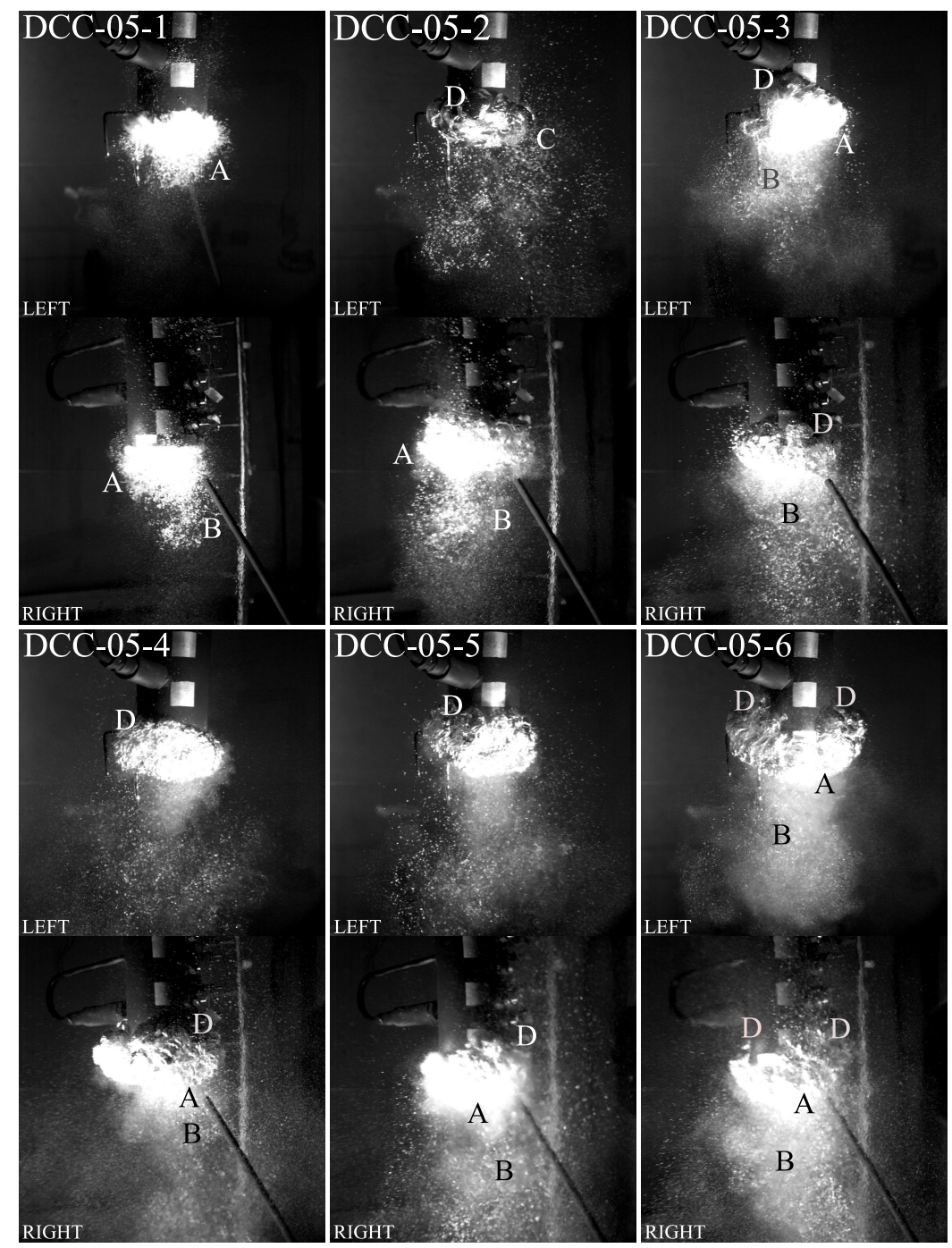

Figure 3: Challenges in image processing of different runs DCC-05-1...DCC-05-6 using left and right cameras. (A) Blurred overexposed edge of the bubble, (B) bright swarms of small bubbles, (C) transparent, hard to recognize bubbles, and (D) shadowed edges of the bubbles were the most common challenges during the DCC-05 experiment. Camera: Phantom Miro M/R/LC110 with $24 \mathrm{~mm}$ lens at an aperture of 12.4 at a framerate of 300 fps. 
high-speed cameras with $24 \mathrm{~mm}$ f1.8-22 lenses operating at a framerate of 300 fps. 300 fps was chosen due to the limited recording capacity and because it allowed a longer recording time. One camera was recording at the bottom of the pool, under the blowdown pipe, and the two others were recording from the side of the pool, almost perpendicularly to each other (see Fig. 1). Various thermocouples and pressure transducers recorded numerical data within the pool and blowdown pipe and stress strain sensors at the pool bottom. A typical view from each camera is shown in Fig. 4 .

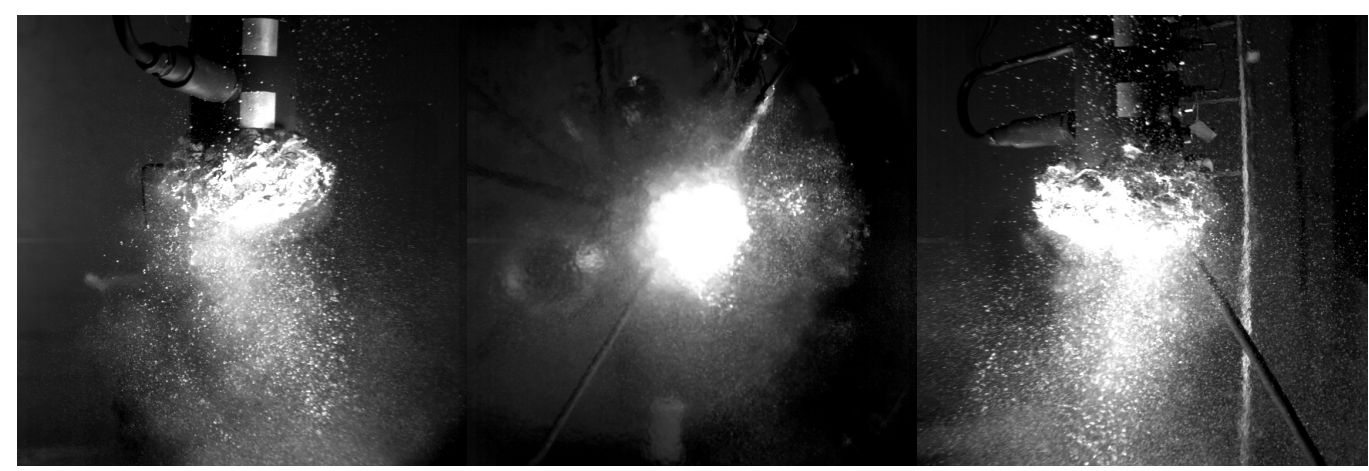

Figure 4: Typical frames from left, bottom and right side cameras. $t=45.72 \mathrm{~s}$, estimated volume $V=3256 \mathrm{~cm}^{3}$ and surface area $A=1696 \mathrm{~cm}^{2}$.

Further information of the DCC-05 experiment is documented in (Puustinen et al., 2014).

\section{Pattern recognition and data analysis algorithm}

\subsection{Development of the algorithm}

The main purpose of the pattern recognition algorithm was to improve knowledge of the effects of DCC during chugging in suppression pools. The goal was to evaluate the volumetric size distribution, average surface area, 
velocity and acceleration of the condensing steam bubbles and their chugging frequencies and investigate transport processes at the bubble surface area. The different stages of average-size steam bubble growth and collapse are presented in Fig. 5.

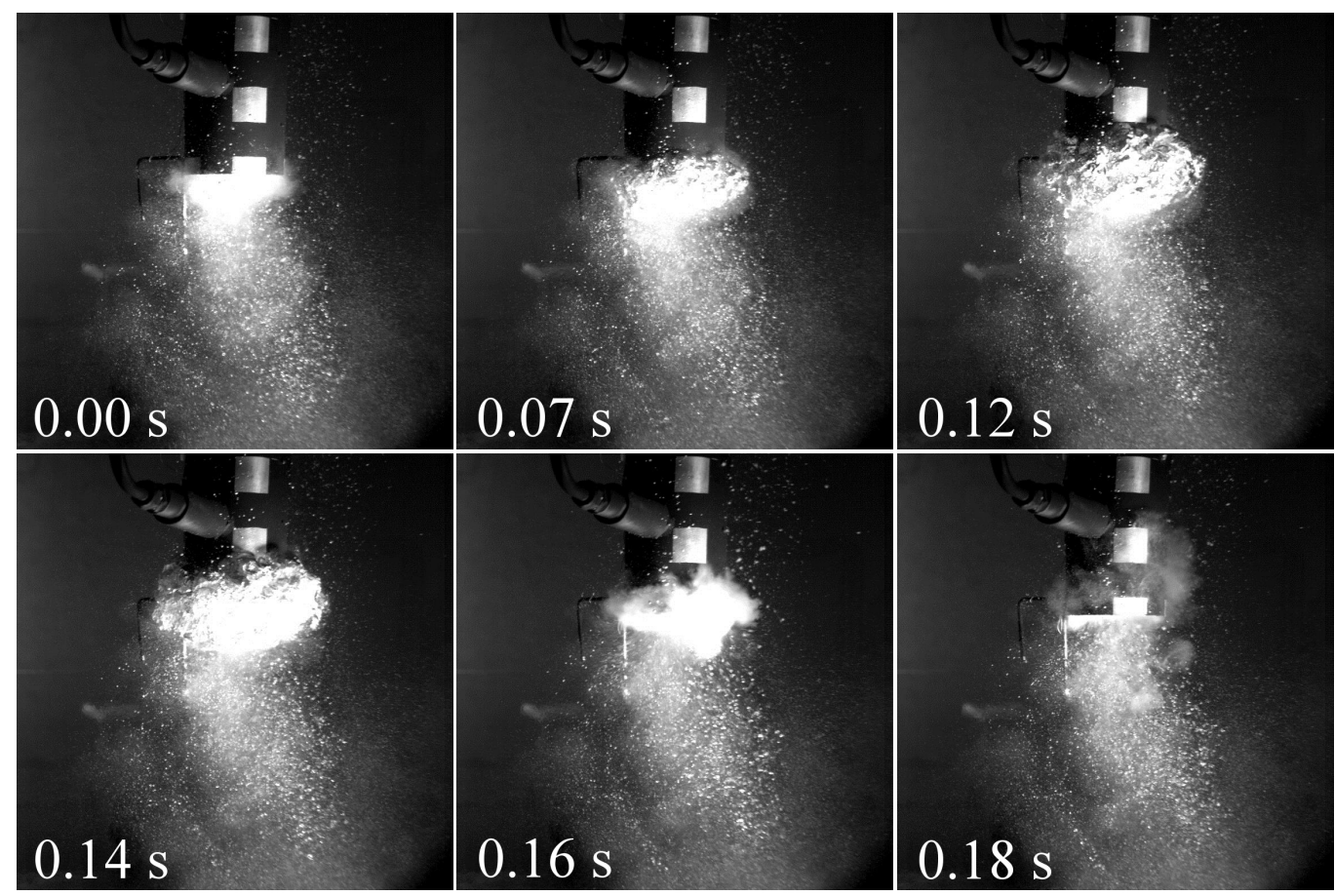

Figure 5: Expansion and collapse of a bubble during the DCC-05-4 test.

The image processing functions of MATLAB software (MATLAB, 2017) were used for construction of the pattern recognition and data analysis algorithm. The first version of the pattern recognition algorithm was introduced earlier in (Hujala, 2013) and (Hujala et al., 2013). The basic operation of the algorithm is presented as a flow diagram in Fig. 6.

The video sample recorded during the DCC-05-4 test was cut into frames. The resolution of each frame was $768 \times 768$ pixels. From every frame, an 


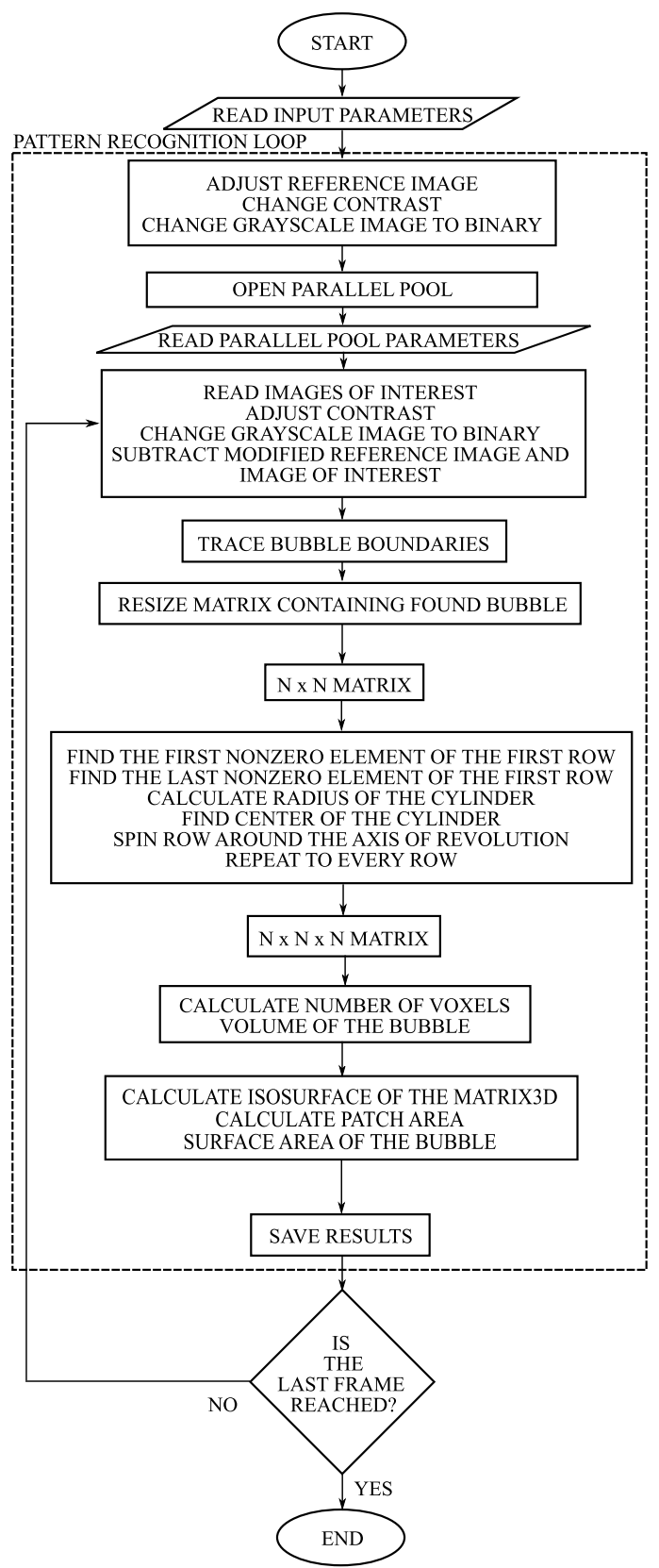

Figure 6: Simplified flow diagram of the pattern recognition algorithm 
empty background image was removed in a way that only the changes - the bubbles - remain. Disturbing bright objects such as reflecting structures of the facility were removed. The boundaries of the bubbles were then identified from black-and-white images. An example of identified bubble boundaries is presented in Fig. 7. An animation of the pattern recognition process is available in the supplementary material of the online version of this article.

As the right-side camera images were noticed to be of poor quality, as shown earlier in Fig. 3, due to blurred, overexposed or shadowed edges and large swarms of small bubbles between the pipe and the camera, images from the right-side camera were not utilized further. A part of bubble shape information was lost due to the absence of images from this camera. Fortunately, the bottom camera data indicated that the bubbles were symmetrically rounded during the DCC-05 test. For this reason, the data of the single side camera was considered to be a sufficient representation of the chugging bubbles in this case. The side profile of the bubbles were known to be arbitrary shaped, e.g., flat, round or semi-circular. A voxel-based method has been used successfully to evaluate the surface of brain images (Windreich et al., 2003), and brain images are known to be arbitrary shaped, and this approach was thus selected for evaluation of the bubble volumes. Fitting of ellipses to the images and evaluating the volume of a spheroid would have been an alternative solution for evaluation of the shape and size of the bubbles (Tanskanen et al., 2014b).

The identified bubbles were processed row by row. Recognized binary images contained only a white side profile of a bubble in a black background. The number of nonzero elements - that is to say, white pixels - of every row 


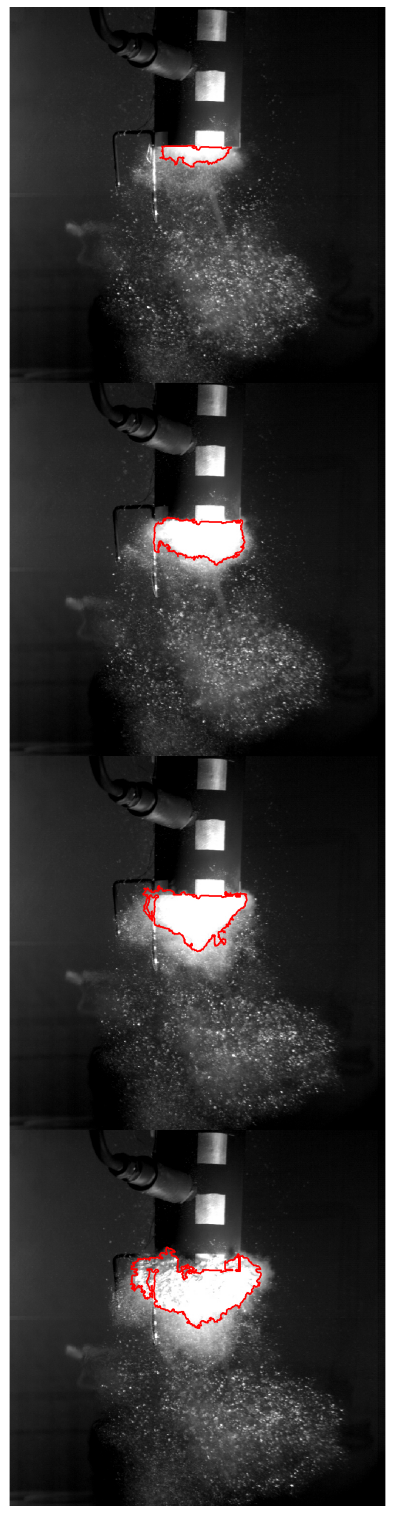

Figure 7: Pattern recognition process. Identified bubble boundaries are marked as red. Some errors of recognition can be seen at the top of the bubble, near to the outlet of the blowdown pipe. 
was calculated and the center of mass evaluated. The line with height of one pixel was rolled over to its center of mass, which produced a cylindrical plate. The sum of the cylindrical plates of each nonzero row gives the volume $V$ of the bubble in voxels:

$$
V=\sum_{i=\text { first row }}^{\text {last row }} \pi\left(\frac{d_{i}}{2}\right)^{2} h_{i}
$$

where $d_{i}$ is the number of nonzero elements in the $i^{\text {th }}$ row and $h_{i}$ is the height of a row.

Calculating the surface area $A$ from the sphere made using voxels overestimates the surface area significantly, so smoothing of the sharp edges was carried out.

The surface of a bubble was created using an isosurface function which extracts isosurface data - faces $\mathrm{F}$ and the vertices $\mathrm{V}$ - in separate arrays from volume data. From vertex array $\mathbf{V}$, triangle vertices $r_{1}, r_{2}$ and $r_{3}$ were created:

$$
\begin{aligned}
& r_{1, s}=\mathbf{V}(\mathbf{F}(\mathbf{s}, \mathbf{1}),:) \\
& r_{2, s}=\mathbf{V}(\mathbf{F}(\mathbf{s}, \mathbf{2}),:) \\
& r_{3, s}=\mathbf{V}(\mathbf{F}(\mathbf{s}, \mathbf{3}),:)
\end{aligned}
$$

where $s$ is the $s^{\text {th }}$ element of the face array $\mathbf{F}$. The vectors $\mathbf{v}_{1}$ and $\mathbf{v}_{2}$ from vertices 1, 2 and 3 are:

$$
\begin{aligned}
& \mathbf{v}_{1}=r_{2}-r_{1} \\
& \mathbf{v}_{2}=r_{3}-r_{1} .
\end{aligned}
$$

Vectors $\mathbf{v}_{1}$ and $\mathbf{v}_{2}$ delimited the parallelogram as shown in Fig. 8 . 


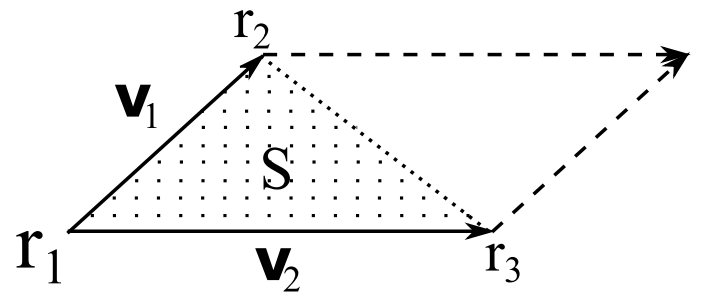

Figure 8: Calculation of the surface area. Triangle vertices $r_{1}, r_{2}$ and $r_{3}$. Vectors $\mathbf{v}_{1}$ and $\mathbf{v}_{2}$ define the parallelogram. A patch $S$ (dotted area) is an area of a triangle defined by the vectors, which is half of the area of the parallelogram.

The surface area $A$ of the bubbles can be calculated using these parallelograms as:

$$
A=\sum_{i=1}^{s}\left(S_{i-1}+0.5 \cdot\left|\mathbf{v}_{1, i} \times \mathbf{v}_{2, i}\right|\right)
$$

where $S_{i-1}$ is the area of each patch, half of the area of the paralleogram and $S_{0}=0$. Spheres with radius of $r=10$ pixels constructed using voxels and cylindrical plates with and without a smooth isosurface are presented in Fig. 9.

The axial velocity and acceleration of the condensing bubbles were estimated using a box ratio method (Hujala, 2013). In this method, just a thin region of interest is considered as shown in Fig. 10. A rectangle of width 35 pixels $(\approx 2.78 \mathrm{~cm})$ and height of 344 pixels $(\approx 27.3 \mathrm{~cm})$ was selected in the middle of the blowdown pipe outlet in a way that its upper border was at the outlet of the pipe. The change in the lower border of the bubbles was investigated and the average fluctuation of the bubbles recorded.

The velocity $\mathbf{v}(n)$ and acceleration $\mathbf{a}(n)$ in the image of interest $n$ at framerate Fs were evaluated using forward difference as presented in equations (8) and (9) respectively. $N$ is the total number of images. 

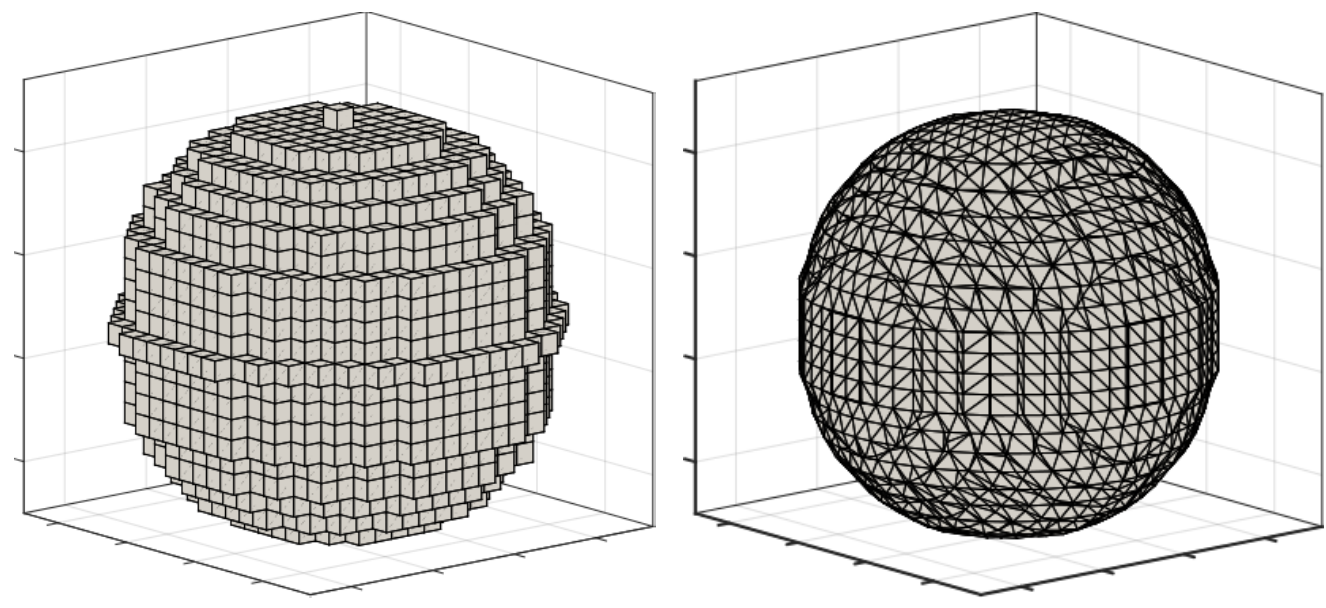

Figure 9: Spheres with radius of $r=10 \mathrm{px}$ created using the voxel-based method (left). At right, the same sphere after use of the isosurface function and smoothing for evaluation of the surface area.

$$
\begin{gathered}
\mathbf{v}(n)= \begin{cases}\mathrm{Fs}(-y(n+1)-(-y(n))), & \text { when } n=1 \\
\frac{\mathrm{Fs}}{2}(-y(n+1)-(-y(n-1))), & \text { when } 2 \leq n \leq N\end{cases} \\
\mathbf{a}(n)= \begin{cases}\mathrm{Fs}^{2}(-y(n+2)-2(-y(n+1))+(-y(n))), & \text { when } n=1 \\
\mathrm{Fs}^{2}(-y(n+1)-2(-y(n))+(-y(n-1))), & \text { when } 2 \leq n \leq N\end{cases}
\end{gathered}
$$

In this study, only the vertical direction of the velocity and acceleration has been evaluated; evaluation will be extended to other directions in future work.

The chugging frequency, i.e. the frequency at which periodic chugging condensation oscillations occur, has been a topic of interest in fluid oscillation measurement since the 1970s (Aya et al., 1980). The transient volume data produced by the algorithm makes it possible to evaluate the most probabilistic chugging frequencies using fast Fourier transform (FFT). 


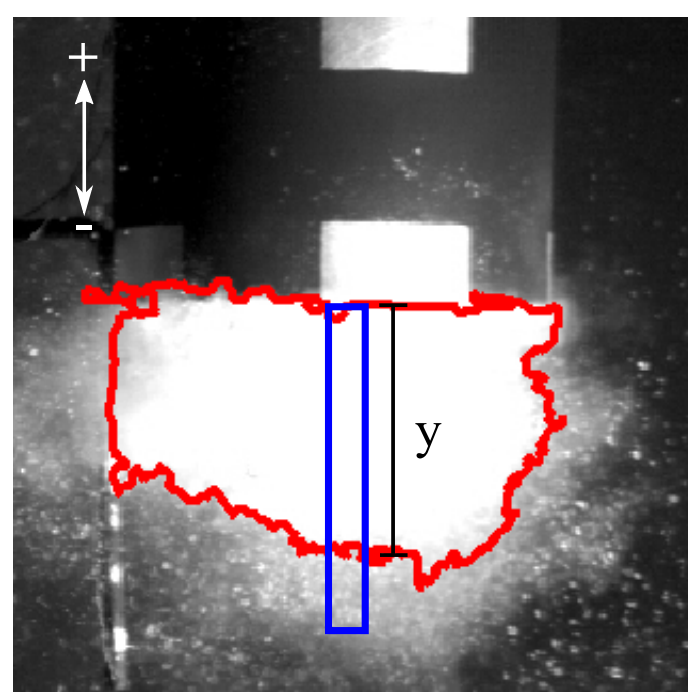

Figure 10: Evaluation of the $y$-distance for velocity and acceleration calculations. The blue rectangle represents the ratio box (not in scale). In every image $n$, the average of the $y$-distance inside the rectangle was measured and velocity $\mathbf{v}(n)$ and acceleration $\mathbf{a}(n)$ evaluated using the forward difference method. 


\subsection{Error estimation}

Due to the challenging camera set-up in the test, many approximative actions had to be included in the pattern recognition algorithm to analyse the data. The number and size of the observation windows were limited in the test facility in order to maintain its ability to withstand large dynamical loads. Thus, the three high-speed cameras were put in places which already existed instead of drilling new windows in the facility walls. In the blowdown experiments with the DN100 blowdown pipe, the bubbles can be said to be axisymmetric but still closer to knobbly ellipsoids than spheres. Also the halogen lamp lighting of the PPOOLEX test facility is challenging and a part of the bubbles are always lost. Lighting limitations made the right-side camera images so blurry - due to the large swarms of small bubbles and the blurryness of the stratified warm water between the camera and the pipe that the frames could not be used. The same problem was found with the bottom camera. Therefore, cylinder plates were chosen for the evaluation of the bubble volume even though their use could lead to larger errors with non-rounded bubbles.

Relative error of the volume of the cylinder has been calculated as follows. Eq. (1) constructed the volume of the bubble using cylinder plates. Radius $r_{i}$ of the cylinder is calculated in pixels $M_{i}$ and converted to metric units by multiplying pixels by the size of one pixel $d$. Using the radius of the cylinder, the total volume of the bubble is:

$$
V=\sum_{i=1}^{N} \pi r_{i}^{2} h_{i}
$$

where $N$ is the total number of the cylinders, and $r_{i}$ and $h_{i}$ are the radius and height of the cylinder $i$ respectively. Height is always a size of one pixel 
$\left(h_{i}=d\right)$ and the radius is a pixel multiplied by the number of pixels $M_{i}$ $\left(r_{i}=M_{i} d\right)$.

$$
V=\sum_{i=1}^{N} \pi\left(M_{i} d\right)^{2} d=\pi d^{3} \sum_{i=1}^{N} M_{i}^{2}
$$

The uncertainty of $N$ is assumed to be zero. The error estimation for the volume $V$ using the total differential is:

$$
\left|\frac{\Delta V}{V}\right| \leq \frac{1}{V}\left(\left|\frac{\partial V}{\partial d}\right||\Delta d|+\sum_{i=1}^{N}\left|\frac{\partial V}{\partial M_{i}}\right|\left|\Delta M_{i}\right|\right)
$$

The uncertainty of $M_{i}$ is assumed to be constant, i.e. $\Delta M_{i}=\Delta M$, thus

$$
\frac{\Delta V}{V} \leq \frac{3 \Delta d}{d}+\frac{2 \Delta M \sum_{i=1}^{N} M_{i}}{\sum_{i=1}^{N} M_{i}^{2}}
$$

When the error of the size of one pixel is $\Delta D=2 \times 10^{-3} \mathrm{~cm}$ and the size of one pixel is $D=79.4 \times 10^{-3} \mathrm{~cm}$, and the error of the number of pixels is $\Delta M=1$, the relative error of the volume of the cylinders $\left|\frac{\Delta V}{V}\right|$ for different cylinder radii is as presented in Fig. 11 .

Relative error less than $10 \%$ for volume with radii larger than $6.5 \mathrm{~cm}$ is suitable, if it is taken into account that the error can be decreased by increasing the resolution of the images or zooming the camera in future experiments.

Relative error of the surface area by using cylinder plates is practically unfeasible to calculate analytically, but it can be estimated using hypothetical spheres produced using the algorithm and comparing them to theoretical values of the volume and surface area of spheres with the same radii. Hypothetical synthetic spheres created using the pattern recognition algorithm were introduced in Fig. 9. When comparing evaluated hypothetical synthetic 


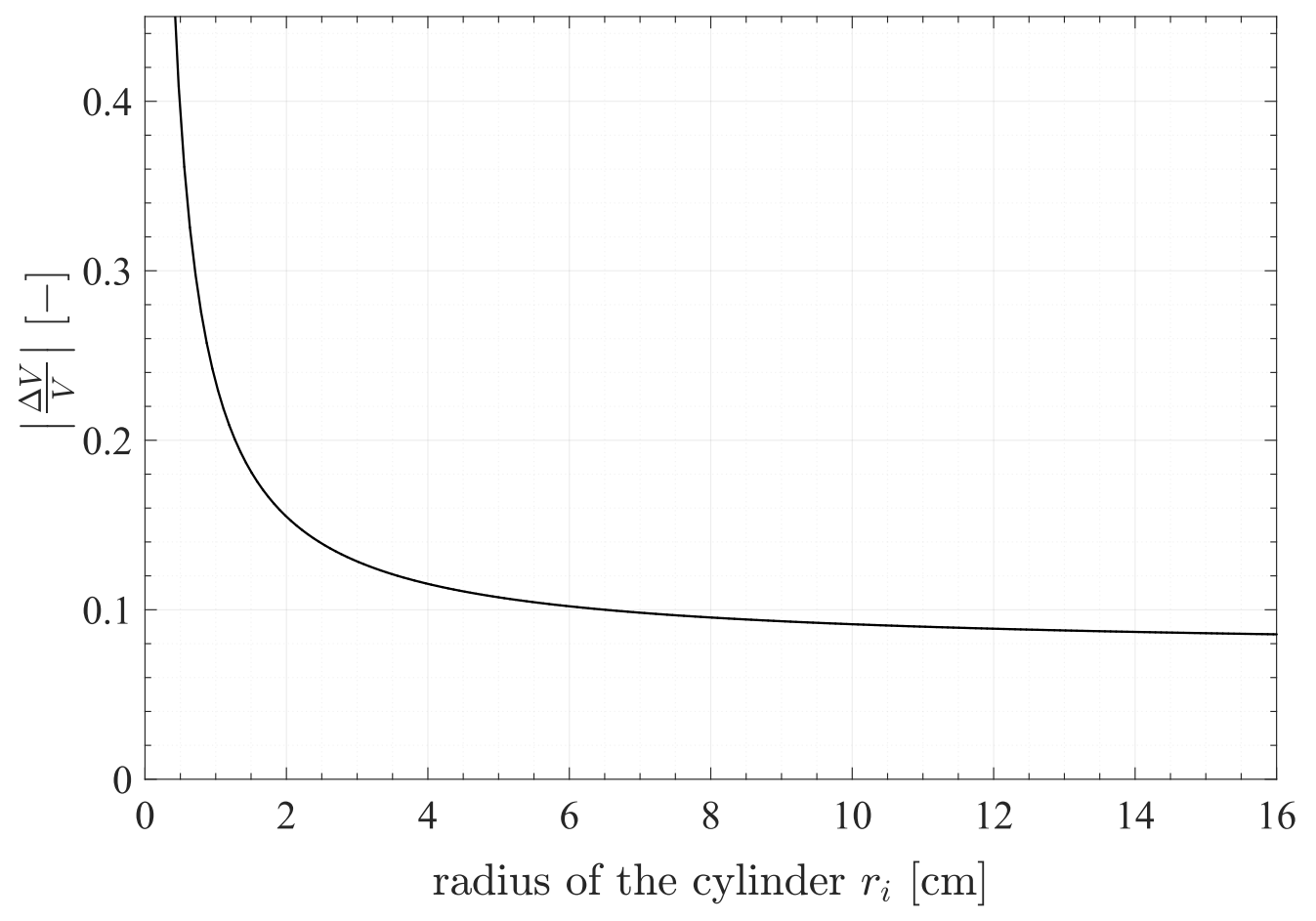

Figure 11: Relative error of the volume of the cylinder for different cylinder radii. The error drops under the $10 \%$ with radii larger than $6.5 \mathrm{~cm}(\approx 82 \mathrm{px})$.

sphere volume, Eq. (1), and surface area, Eq. (7), with different sphere radii $r_{i}$ to theoretical values of the sphere volume $V_{\text {sphere }}=\frac{4}{3} \pi r_{i}^{2}$ and to the surface area $A_{\text {sphere }}=4 \pi r_{i}^{2}$, the errors drop under $1 \%$, if the radius of the sphere is more than $30 \mathrm{px}(\approx 2.4 \mathrm{~cm})$ as shown in Fig. 12 .

The nearer the steam bubbles are to pure spheres, the better is the performance of the pattern recognition algorithm and the more accurate the volumetric and surface area estimations. Combining the above errors together, it can be said that the algorithm is suitable for estimation of the temporal volumetric and area changes of the steam bubbles as the effect of 


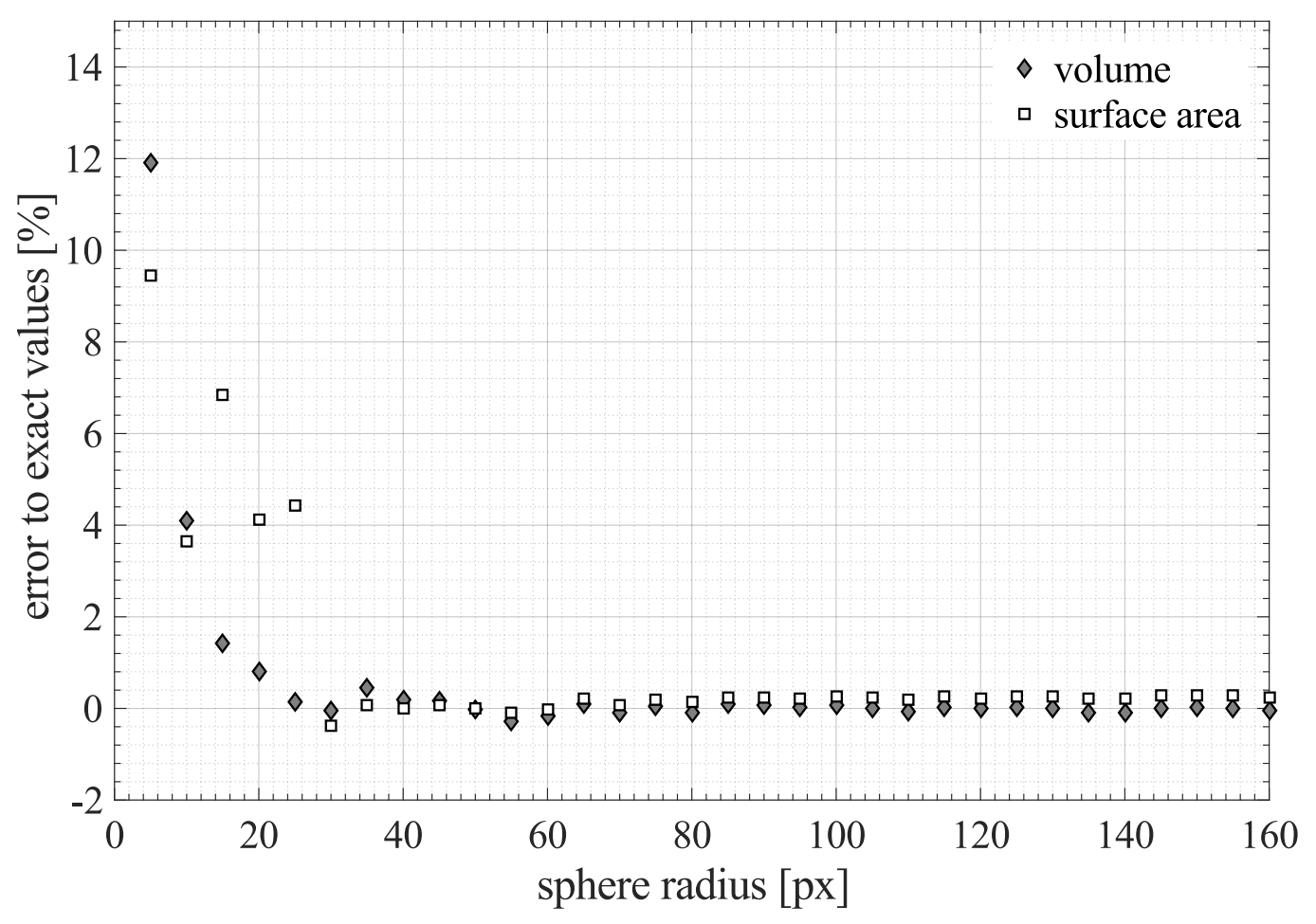

Figure 12: Volume and surface area errors of hypothetical spheres, produced using the algorithm for circles with different radii $r_{i}$, compared to exact values of theoretical spheres $V_{\text {sphere }}=\frac{4}{3} \pi r_{i}^{3}$ and $A_{\text {sphere }}=4 \pi r_{i}^{2}$.

systematic errors diminish even further in transient study.

\section{Results}

The DCC-05-4 experiment was investigated using the pattern recognition and data analysis algorithm. A total length of $48 \mathrm{~s}$ of video material was recorded. At a framerate of $300 \mathrm{fps}$, a total of 14426 frames were stored. Evaluated surface areas and volumes of the bubbles during the experiment are presented in Fig. 13 .

Estimated surface area varies between $0.05 \mathrm{~m}^{2}$ to $0.2 \mathrm{~m}^{2}$. The volumes of 


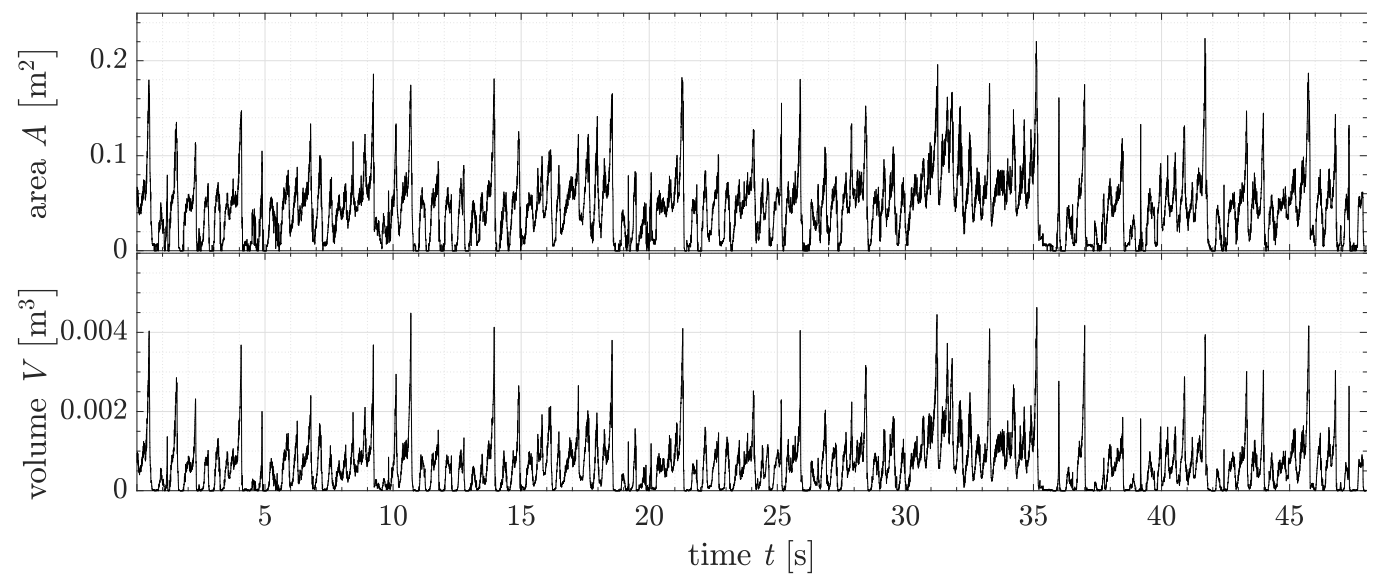

Figure 13: Estimated surface areas $A$ (top) and volumes $V$ (bottom) of the bubbles during the DCC-05-4 experiment using pattern recognition algorithm.

the largest bubbles are near to $4 \mathrm{dm}^{3}$. The distance between the surface of the bubble and the blowdown pipe outlet in the $y$-direction, the estimated velocity and the vertical acceleration of the bubbles evaluated as described in Chapter 3.1 are shown in Fig. 14.

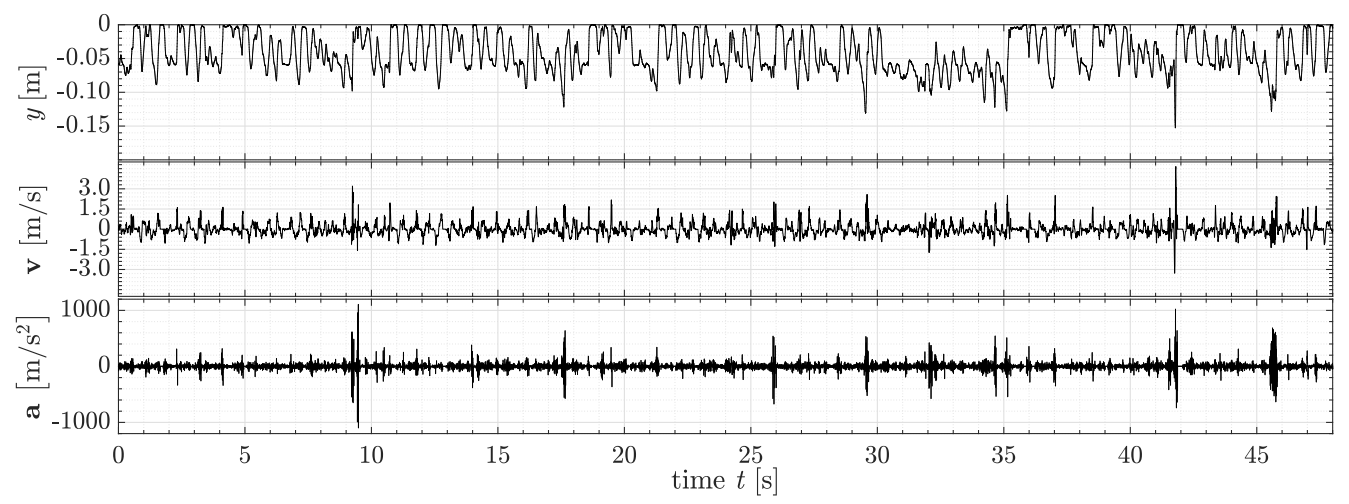

Figure 14: Distance between the bubble surface and blowdown pipe outlet $y$ (top), velocity of the bubble growth and collapse $\mathbf{v}$ (middle) and the vertical acceleration of growing and collapsing bubbles a (bottom) during the DCC-05-4 experiment. 
The largest bubbles reached $-0.15 \mathrm{~m}$ below the blowdown pipe during expansion with a velocity of $-3 \mathrm{~m} \mathrm{~s}^{-1}$ and then condensed with a velocity as high as $4.5 \mathrm{~ms}^{-1}$. The acceleration between the growth and break up of the bubble exceeds almost $2000 \mathrm{~m} \mathrm{~s}^{-2}$. A closer view of acceleration data is presented in Fig. 15.
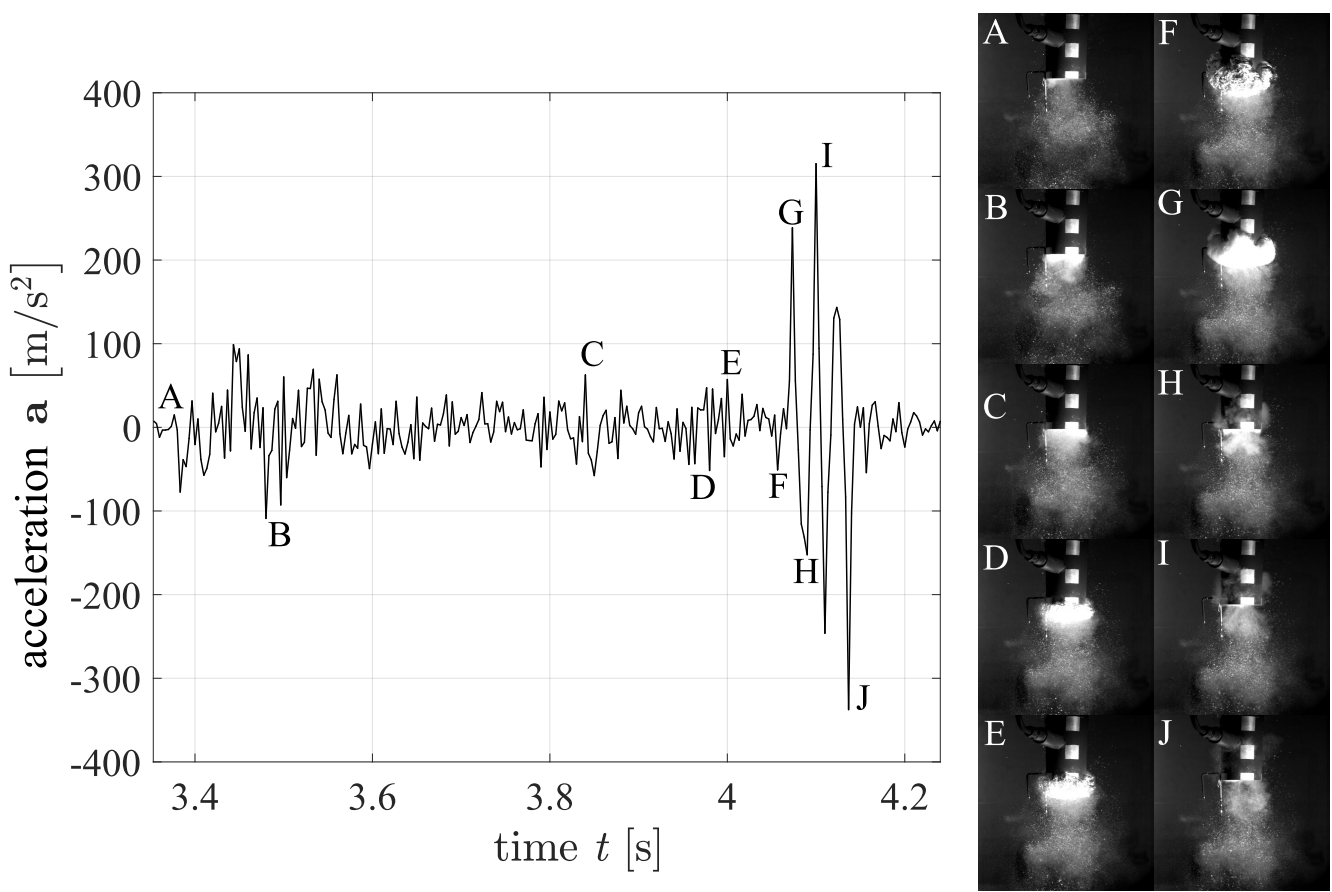

Figure 15: Short sample of acceleration data and related bubble modes A to J.

The velocity and acceleration values are crucial when choosing nodalization resolution and interfacial area density models for Eulerian two-fluid CFD simulations of chugging cases (Patel et al., 2017). The commonly used interfacial area density calculated from the gradient of the void fraction yields effectively the minimum surface area allowed by the nodalization density (Pellegrini et al. 2015). Interfacial details smaller than the node size are 
filtered out if no additional sub-grid scale interfacial area density models are included. Interfacial area increase due to interfacial instabilities can reach almost arbitralily high values, but a preliminary maximum for node size can be assumed to be at least less than the critical wave length for the RayleighTaylor instability (Patel et al., 2017). However, better results can be obtained by decreasing node size further. Critical wavelength $\lambda_{c}$ is:

$$
\lambda_{c}=2 \pi \sqrt{\frac{\sigma}{a\left(\rho_{l}-\rho_{v}\right)}},
$$

where $\sigma$ is the surface tension, $a$ is the acceleration, $\rho_{l}$ is the density of the water and $\rho_{v}$ is the density of the steam (Ishii and Hibiki, 2011). High acceleration due to chugging limits the node size in CFD simulations to $1.0 \mathrm{~mm}-1.3 \mathrm{~mm}\left(\mathbf{a}=1100 \mathrm{~m} \mathrm{~s}^{-2}, p=3.1\right.$ bar $)$ in the DCC-05-4 case. At the same time, predominant wavelength $\lambda_{m}$ :

$$
\lambda_{m}=2 \pi \sqrt{\frac{3 \sigma}{a\left(\rho_{l}-\rho_{v}\right)}}
$$

is $1.7 \mathrm{~mm}-2.4 \mathrm{~mm}$.

The chugging frequencies were acquired using FFT for the volume data. The FFT image is shown in Fig. 16.

The frequencies are concentrated at low frequencies, but two higher frequencies are also visible, around $53.4 \mathrm{~Hz}$ and $126.4 \mathrm{~Hz}$. The low frequencies $0.6 \mathrm{~Hz} \pm 0.3 \mathrm{~Hz}$ and around $2.1 \mathrm{~Hz}$ can be confirmed to be very near the chugging frequencies seen also with ocular investigation. In ocular investigation, the video material was reviewed frame by frame and the frequencies calculated manually.

The possible effect of electric grid noise was studied comparing FFT of the 


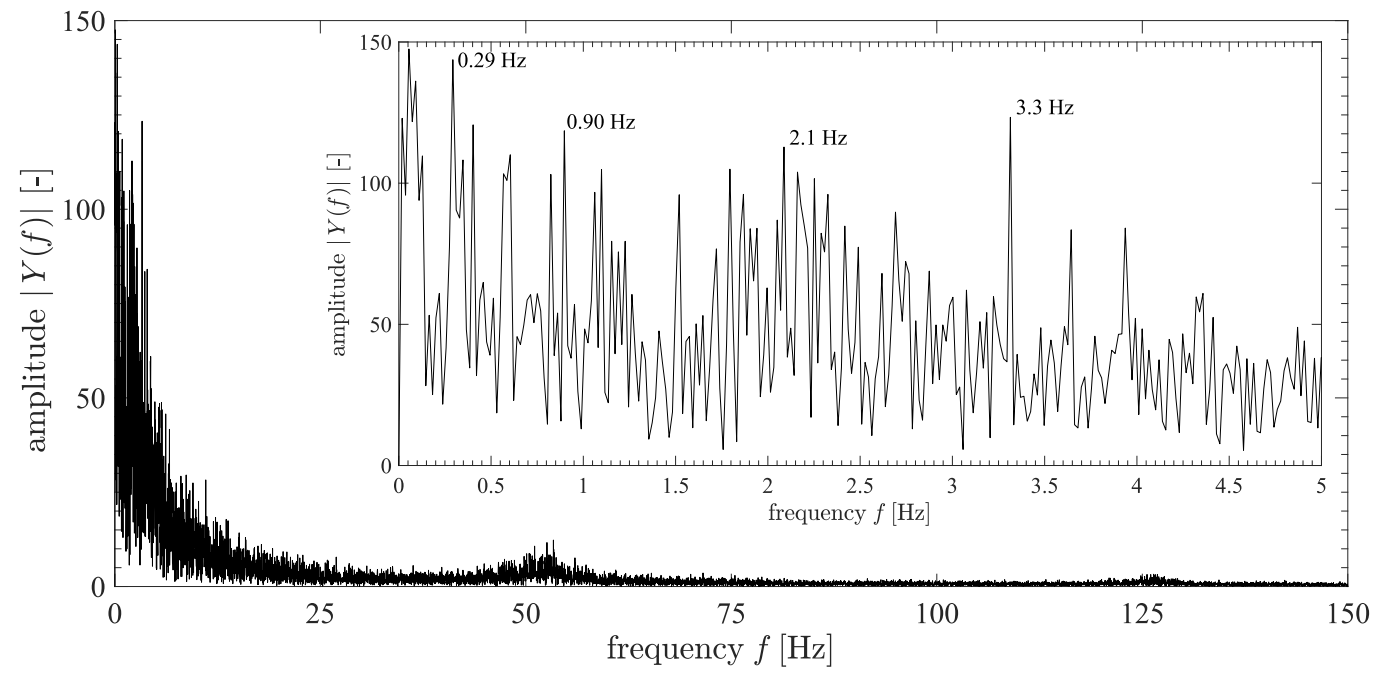

Figure 16: FFT of the DCC-05-4 volume data. The most probable chugging frequencies $f$ were estimated as between $0.29 \mathrm{~Hz}$ to $3.3 \mathrm{~Hz} .|Y(f)|$ is an absolute value of an amplitude of each frequency $f$ and $t$ is time.

pressure transducer data during the experiment (steam injection on) to the data without steam injection by making FFT amplitudes comparable. Two pressure transducers in different places were compared. Pressure transducer $\mathrm{p}_{5}$ was in the pool water, $5 \mathrm{~cm}$ away from the blowdown pipe outlet, and pressure transducer $\mathrm{p}_{6}$ was at the bottom of the suppression pool. FFTs of the pressure transducer data with and without the steam injection are shown in Fig. 17

When the steam injection is off, the pressure transducer $\mathrm{p}_{6}$ at the bottom of the pool shows a high, sharp signal from the electric grid $(50.0 \pm 0.1) \mathrm{Hz}$ (lower left in Fig. 17), whereas at the middle of the pool, $5 \mathrm{~cm}$ from the blowdown pipe outlet, the grid signal blends into the noise in pressure transducer $\mathrm{p}_{5}$ (top left in Fig. 17). When the steam injection is on, the noise of the 

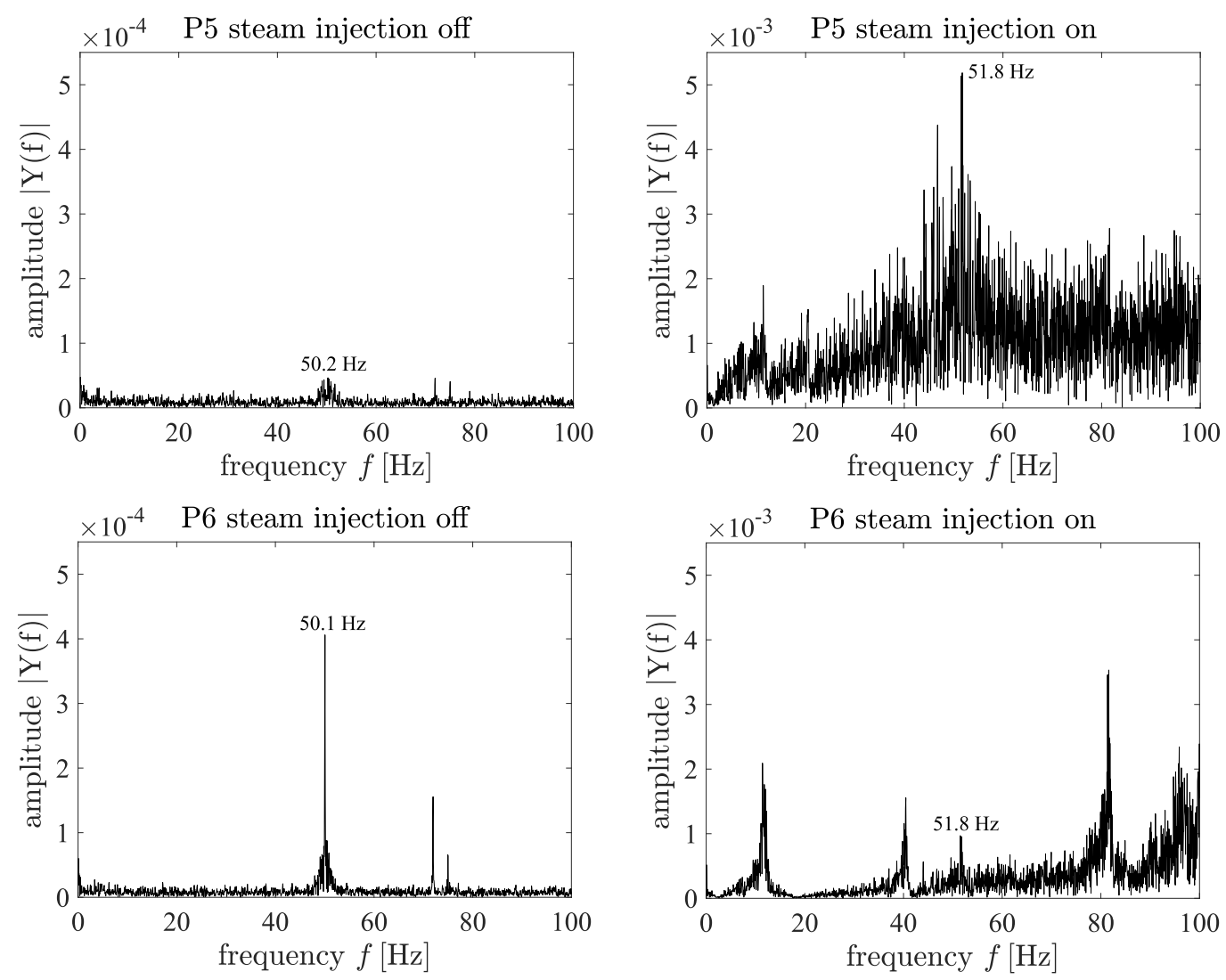

Figure 17: Pressure transducers $\mathrm{p}_{5}$ and $\mathrm{p}_{6}$ FFTs without steam injection (left) and with steam injection (during the experiment) (right). The amplitudes $|Y(f)|$ are made comparable by limiting sample length. Notice the tenfold difference between the amplitudes. 
electricity grid has to vanish in the measured signal, because its amplitude is tenfold lower than pressure oscillations during chugging.

\section{Discussion}

Despite numerous approximations made in the pattern recognition algorithm, the data acquired from the transient phenomena match visual observations of the oscillation frequency. Systematic errors have no significant effect on the final analyses, which are based mostly on the values obtained by differentials of location, i.e. velocity, acceleration and volume/area change rate in FFT. The fluctuation of the bubble volume and surface area can be recorded reliably. The relative error of the volume can be decreased by increasing the resolution of the images or zooming the camera in future experiments.

The velocities of the growing and condensing bubbles are moderate, $\pm 3 \mathrm{~m} \mathrm{~s}^{-1}$, but the acceleration, $\pm 1100 \mathrm{~m} \mathrm{~s}^{-2}$, is remarkable. Acceleration of this magnitude affects inevitably the strength requirements of suppression pool structures. Furthermore, it makes difficult to include delicate intrusive measurement instruments near the vent pipe outlet. Critical wavelength $\lambda_{c}=$ $1.0 \mathrm{~mm}-1.3 \mathrm{~mm}$ limited the maximum node size in CFD simulation to $1 \mathrm{~mm}$, which is still quickly runnable with a few computer cores as a transient 2Daxisymmetric simulation. The chugging frequencies were known to be around $1-4 \mathrm{~Hz}$, calculating visually from the video. The most probable frequencies were estimated to be around $0.29 \mathrm{~Hz}$ to $3.3 \mathrm{~Hz}$, which fits well to expectations. The chugging oscillations are not periodic all the time, so the frequency spikes in FFT spread over a quite wide range. Furthermore, the experiment consists of various bubble types (Hujala et al. 2017) which condense differently. 
Frequency analysis also showed two higher frequencies around $53.4 \mathrm{~Hz}$ and $126.4 \mathrm{~Hz}$. The first frequency is close to the natural frequency of this size of bubbles (Brennen, 2014). The latter frequency seems to be related to the interfacial area oscillations of the bubbles (Hujala et al., 2017). The frequency of the electricity grid is $(50.0 \pm 0.1) \mathrm{Hz}$, which has some effect on FFT evaluated using pressure transducer data. $53.4 \mathrm{~Hz}$ is so far from the grid frequency of $50 \mathrm{~Hz}$ that the $53.4 \mathrm{~Hz}$ frequency must be due to physical phenomena in the system, and not due to electricity grid excitation. The frequency analysis presented elsewhere showed that the $53.4 \mathrm{~Hz}$ is from the surface area of the bubbles (Hujala et al., 2017). Halogen lamps, which produce steady light intensity independent of grid frequency, were used in the DCC-05 experiment. Considering these points, the algorithm looks promising for investigation of surface events of bubbles, but more frequency analysis with other measured data is needed to establish the sources for each frequency observed.

\section{Conclusions}

The pattern recognition and data analysis algorithm presented in this work is able to acquire novel non-intrusive measurement data about chugging direct contact condensation. The algorithm is well suited for symmetrical bubbles but not for precise evaluation of the volume and surface area, especially of small and very asymmetric steam bubbles. In addition to suppression pool problems, the algorithm can be applied to video material from other measurement environments too. Higher grade data from smaller scale facilities could be used to further validate the algorithm. More cylindrically

symmetric bubbles are preferable for the algorithm. Such bubbles can be 
reached with more stable flow modes such as bubbly and slug flows within ducts or in some sparger blowdown phases. The performance of the algorithm can be benchmarked against wire mesh sensor (WMS) and particle image velocimetry (PIV) measurements.

The algorithm works well for estimation of growing and breaking up velocities and acceleration of the bubbles and gives significant information about events in the direct contact condensation process. The algorithm also gives valuable information about critical wavelength and maximum node size in CFD simulations. FFT and other frequency analysis methods are suitable means for comparison of pressure oscillation data and structure wall strain rate sensor data to the pattern recognition data of oscillating bubbles. Since the conditions of the PPOOLEX facility are challenging and some approximation always needs to be done, a framerate of at least $1000 \mathrm{fps}$ should be used when possible. Furthermore the possibility of image zooming should be considered for a closer view of the bubbles and consequently better quality pattern recognition. Moreover, image zooming or increasing the resolution would decrease the amount of relative error of the algorithm.

\section{Acknowledgements}

The research leading to these results was partly funded by the Finnish Nuclear Waste Management Fund (VYR) via the Finnish Research Programs on Nuclear Power Plant Safety, SAFIR2014 and SAFIR2018. The authors gratefully acknowledge all this support. The authors wish to thank Mr. Peter Jones, who assisted in language revision of the manuscript. 


\section{References}

Aust, E., Schultheiss, G., Seeliger, D., McCauley, E., 1983. Experimental Results about Dynamic Load Mitigation for BWR-Pressure Suppression Containments under LOCA-Conditions, in: J - Loading Conditions and Structural Analysis of Reactor Containment, IASMiRT. pp. 43-50. http: //www.lib.ncsu.edu/resolver/1840.20/26068.

Aya, I., Kobayashi, M., 1983. Pressure and fluid oscillations in vent system due to steam condensation, (II) high-frequency component of pressure oscillations in vent tubes under at chugging and condensation oscillation. Journal of Nuclear Science and Technology 20, 213-227.

Aya, I., Nariai, H., 1987. Boundaries between regimes of pressure oscillation induced by steam condensation in pressure suppression containment. Nuclear Engineering and Design 99, 31-40.

Aya, I., Nariai, H., Kobayashi, M., 1980. Pressure and fluid oscillations in vent system due to steam condensation, (I) experimental results and analysis model for chugging. Journal of Nuclear Science and Technology $17,499-515$.

Bestion, D., 2014. The difficult challenge of a two-phase CFD modelling for all flow regimes. Nuclear Engineering and Design 279, 116-125.

Brennen, C., 2014. Cavitation and Bubble Dynamics. 1st edn. Cambridge University Press. ISBN 978-1-107-64476-2.

Brouillette, M., 2002. The Richtmyer-Meshkov instability. Annual Review of Fluid Mechanics 34, 445-468. 
Chan, C.K., Lee, C.K.B., 1982. A regime map for direct contact condensation. International Journal of Multiphase Flow 8, 11-20.

Drazin, P.G., 2002. Introduction to Hydrodynamic Stability. Cambridge Texts in Applied Mathematics, Cambridge University Press.

Gregu, G., Takahashi, M., Pellegrini, M., Mereu, R., 2017. Experimental study on steam chugging phenomenon in a vertical sparger. International Journal of Multiphase Flow 88, 87-98.

Hujala, E., 2013. Evaluation of Bubble Formation and Break Up in Suppression Pools by Using Pattern Recognition Methods. Master thesis. Lappeenranta University of Technology. LUT Energy, Lappeenranta, Finland. Available online: http://urn.fi/URN:NBN : fi-fe201304082709.

Hujala, E., Tanskanen, V., Hyvärinen, J., 2017. Frequency analysis of chugging condensation in pressure suppression pool system with pattern recognition, in: The 17th International Topical Meeting on Nuclear Thermal Hydraulics (NURETH-17), Xi'an, Shaanxi, China, September 3-8.

Hujala, E., Tanskanen, V., Puustinen, M., 2013. Progress in the development of pattern recognition algorithm for the PPOOLEX video data. Technical Report. Lappeenranta University of Technology, School of Technology, Laboratory of Nuclear Engineering.

Ishii, M., Hibiki, T., 2011. Thermo-Fluid Dynamics of Two-Phase Flow. 2nd edn. Springer Science+Business Media. ISBN 978-1-4419-7984-1, e-ISBN 978-1-4419-7985-8. 
Issa, S.A., Weisensee, P., Macian-Juan, R., 2014. Experimental investigation of steam bubble condensation in vertical large diameter geometry under atmospheric pressure and different flow conditions. International Journal of Heat and Mass Transfer 70, 918-929.

Kukita, Y., Namatame, K., Shiba, M., 1984. The LOCA air-injection loads in BWR Mark II pressure suppression containment systems. Nuclear Engineering and Design 77, 117-129.

Kukita, Y., Namatame, K., Takeshita, I., Shiba, M., 1987. LOCA steam condensation loads in BWR Mark II pressure suppression containment system. Nuclear Engineering and Design 102, 225-228.

Lahey, R., Moody, F., 1993. The Thermal-Hydraulics of a Boiling Water Reactor. 2 ed., American Nuclear Society, La Grange Park, Illinois, USA. ISBN: 0-89448-037-5.

MATLAB, 2017. version 9.2.0 (R2017a). The MathWorks Inc., Natick, Massachusetts, USA.

Meshkov, E.E., 1969. Instability of the interface of two gases accelerated by a shock wave. Soviet Fluid Dynamics 4, 101-104.

Mimouni, S., Mechitoua, N., Foissac, A., Hassanaly, M., Ouraou, M., 2011. CFD modeling of wall steam condensation: Two-phase flow approach versus homogeneous flow approach. Science and Technology of Nuclear Installations 2011.

Motoaki Utamura, K.M., Uozumi, H., 1984. Numerical analysis on pressure 
propagation in pressure suppression system due to steam bubble collapse. Journal of Nuclear Science and Technology 21, 279-287.

Patel, G., Tanskanen, V., Hujala, E., Hyvärinen, J., 2017. Direct contact condensation modeling in pressure suppression pool system. Nuclear Engineering and Design 321, 328-342.

Pellegrini, M., Araneo, L., Ninokata, H., Ricotti, M., Naitoh, M., Achilli, A., 2016. Suppression pool testing at the SIET laboratory: experimental investigation of critical phenomena expected in the Fukushima Daiichi suppression chamber. Journal of Nuclear Science and Technology 53, 614629.

Pellegrini, M., Naitoh, M., Josey, C., Baglietto, E., 2015. Modeling of Rayleigh-Taylor instability for steam direct contact condensation, in: The 16th International Topical Meeting on Nuclear Reactor Thermal Hydraulics (NURETH-16), Chicago, IL, August 30-September 4, p. 15.

Puustinen, M., Kyrki-Rajamäki, R., Tanskanen, V., Räsänen, A., Purhonen, H., Riikonen, V., Laine, J., Hujala, E., 2013. BWR Suppression Pool Studies with POOLEX and PPOOLEX Test Facilities at LUT, in: The 15th International Topical Meeting on Nuclear Thermal Hydraulics (NURETH-15), Pisa, Italy, 12-17 May, p. 061.

Puustinen, M., Laine, J., Räsänen, A., Hujala, E., 2014. Chugging Test with DN100 Blowdown Pipe in the PPOOLEX Facility. Technical Report. Lappeenranta University of Technology, Nuclear Safety Research Unit. 
Richtmyer, R.D., 1960. Taylor instability in shock acceleration of compressible fluids. Communications on Pure and Applied Mathematics XIII, 297319.

Simpson, M.E., Chan, C.K., 1982. Hydrodynamics of a subsonic vapor jet in subcooled liquid. Journal of Heat Transfer 104, 271-278.

Strutt, J.W.(Lord Rayleigh)., 1883. Investigation of the character of the equilibrium of an incompressible heavy fluid of variable density. Proceedings of the London Mathematical Society 14, 170-177.

Tanskanen, V., Hujala, E., Puustinen, M., 2014a. Numerical simulation and analysis of PPOOLEX DCC-05 chugging test. Technical Report. Lappeenranta University of Technology, School of Energy Systems, Nuclear Engineering.

Tanskanen, V., Jordan, A., Puustinen, M., Kyrki-Rajamäki, R., 2014b. CFD simulation and pattern recognition analysis of the chugging condensation regime. Annals of Nuclear Energy 66, 133-143.

Taylor, G., 1950. The instability of liquid surfaces when accelerated in a direction perpendicular to their planes. Part I. Proceedings of the Royal Society of London, Series A, Mathematical and Physical Sciences 201, 192 196.

Windreich, G., Kiryati, N., Lohmann, G., 2003. Voxel-based surface area estimation: From theory to practice. Pattern Recognition 36, 2531-2541. 